\title{
Habitat use at fine spatial scale: how does patch clustering criteria explain the use of meadows by red deer?
}

\author{
Annalisa Bellu • Miguel N. Bugalho • \\ Tiago Monteiro-Henriques • José C. Costa • \\ Francisco C. Rego
}

Received: 19 September 2011 /Revised: 24 December 2011 / Accepted: 25 January 2012 /Published online: 6 March 2012

(C) Springer-Verlag 2012

\begin{abstract}
Large mammalian herbivores are keystone species in different ecosystems. To mediate the effects of large mammalian herbivores on ecosystems, it is crucial to understand their habitat selection pattern. At finer scales, herbivore patch selection depends strongly on plant community traits and therefore its understanding is constrained by patch definition criteria. Our aim was to assess which criteria for patch definition best explained use of meadows by wild, free-ranging, red deer (Cervus elaphus) in a study area in Northeast Portugal. We used two clustering criteria types based on floristic composition and gross forage classes, respectively. For the floristic criteria, phytosociological approach was used to classify plant communities, and its objectivity evaluated with a mathematical clustering of the floristic relevés. Cover of dominant plant species was tested as a proxy for the phytosociological method. For the gross forage classes, the graminoids/forbs ratio and the percentage cover of legumes were used. For assessing deer relative use of meadows we used faecal accumulation rates. Patches clustered according to floristic classification better explained selection
\end{abstract}

Communicated by P. Acevedo

Electronic supplementary material The online version of this article (doi:10.1007/s10344-012-0612-8) contains supplementary material, which is available to authorized users.

A. Bellu $(\bowtie) \cdot$ M. N. Bugalho $•$ F. C. Rego

Centre for Applied Ecology "Baeta Neves", Instituto Superior

Agronomia, Technical University of Lisbon (TULisbon),

Tapada da Ajuda,

1349-017 Lisbon, Portugal

e-mail: annalisa@isa.utl.pt

T. Monteiro-Henriques $\cdot$ J. C. Costa

Centro de Botânica Aplicada à Agricultura, Instituto Superior

Agronomia, Technical University of Lisbon (TULisbon),

Tapada da Ajuda,

1349-017 Lisbon, Portugal of patches by deer. Plant community classifications based on phytosociology, or proxies of this, used for characterizing meadow patches resulted useful to understand herbivore selection pattern at fine scales and thus potentially suitable to assist wildlife management decisions.

Keywords Patch definition · Cervus elaphus · Faecal accumulation rate $\cdot$ Foraging habitat use $\cdot$ Hay meadows

\section{Introduction}

Deer populations are generally expanding, both in numbers and geographic range, across the northern hemisphere (Cote et al. 2004) affecting the biodiversity and functioning of ecosystems (Bugalho et al. 2011; Huntly 1991; Rooney and Waller 2003). When managing habitats for conservation it is crucial to understand herbivore selection pattern. Herbivore decisions operate at different spatial scales, varying from the regional to the plant community level (Bailey et al. 1996). At broader scales, topography (Kie et al. 2005), human disturbances (Coulon et al. 2008), predation risk (Fortin et al. 2005; Hebblewhite et al. 2005) or thermal and hiding cover (Mysterud et al. 1999; Partl et al. 2002) are key factors affecting habitat selection. At finer scales (patch and feeding station, sensu Bailey et al. 1996), selection is better explained by forage availability (Johnson et al. 2001) and quality (WallisDeVries et al. 1999). The criteria used for patch definition may affect the observer interpretation of herbivore behaviour (Bowyer and Kie 2006; Kie et al. 2002). According to landscape ecologists, a patch can be defined as a discrete spatial unit distinguished by discontinuities in one or more environmental variables (Wiens 1976). For example, a wet grassland community can be classified as a patch if its plant species composition differs from the surrounding drier grassland area. According to animal ecologists, a patch is better 
defined by a change in the rate of a process or behaviour (Bailey et al. 1996; Senft et al. 1987) as, for example, a change in the foraging sequence of the animal or when it moves or relocates itself to continue feeding (Bailey et al. 1996). However, feeding patches are frequently defined according to the availability and quality of the plant food and mostly based on plant species composition (Clutton-Brock et al. 1982; Gordon 1989a). Red deer (Cervus elaphus) hinds in the island of Rhum, Scotland, for example, selected nutritive rich Agrostis tenuisFestuca rubra and poor Agrostis sp.-Festuca vivipara communities during spring, while stags fed more on herb rich heath and poor Agrostis-Festuca communities throughout the year and on marsh communities in all seasons but summer (Gordon 1989b).

Controlled experiments, dealing with captive animals and artificially created patches, have shown that the selectivity of herbivores depends largely on forage characteristics such as plant digestible protein content (Langvatn and Hanley 1993), plant abundance, spatial distribution of preferred plant species (Chapman et al. 2007; Dumont et al. 2002) or sward structure (Griffiths et al. 2003). However, in natural or semi-natural conditions, environmental variability and forage heterogeneity are more difficult to quantify. In these situations, the way a patch is defined is crucial to understand herbivore selection: the classification methods employed should be considered themselves object of study (Loehle 2011).

In the present study, we analysed red deer spring use of meadows at a fine scale. Our aim was to assess if the plant community level (or patch level, sensu Bailey et al. 1996) was useful to detect patterns in deer use, and which criteria for patch definition permitted a better understanding of red deer use of meadows. We clustered patches according to two different criteria types: floristic classification and gross forage class ratios. Among the floristic criteria we tested the phytosociological classification, following the Zurich-Montpellier school methodology (Braun-Blanquet 1932). To evaluate the objectivity of this approach, we also tested patch classification resulting from mathematical clustering using the total cover of plant species. To assess the possibility of using less timeconsuming methods to discriminate among plant communities, we clustered meadow patches according to the cover of dominant plant species only. For the gross forage type, we used the ratio of graminoids and forbs and the percentage cover of legumes. This may contribute to consolidate criteria for defining patches when investigating herbivore habitat use pattern at fine scales.

\section{Methods}

Study area

The study area is located in the Natural Park of Montesinho (NPM), Northeast Portugal (Fig. 1a, b). NPM is a 75000 ha area, included in the Pan-European network of protected areas Natura 2000. NPM is under the influence of Mediterranean bioclimate (Rivas-Martínez 2007) and it is characterized by a mosaic of deciduous (Quercus pyrenaica) and evergreen (Quercus rotundifolia, Quercus suber) oak woodlands, coniferous plantations (Pseudotsuga menziensii, Pinus pinaster), shrublands (Erica australis, Pterospartum tridentatum, Halimium alyssoides, Cistus ladanifer and Cytisus spp.), and a variety of perennial grasslands mostly belonging to the phytosociological classes of MolinioArrhenatheretea, Nardetea and Stipo-Agrostietea (Aguiar 2001). Mostly, the soils are leptosols and cambisols derived from pre-Ordovician schists (Aguiar 2001).

A system of managed meadows occurs along watercourses and is maintained by local population through traditional irrigation techniques, extensive livestock grazing and hay harvesting. The plant species composition of these meadows varies with soil moisture (Aguiar 2001).

Red and roe deer (Capreolus capreolus) populations occur in the study area at 3 to 4 individuals $/ \mathrm{km}^{2}$ and 1 to 2 individuals $/ \mathrm{km}^{2}$, respectively (Paiva 2004). A stable population of wolves (Canis lupus signatus) is also present in the area.

Sampling units and sampling plots

We selected an area of $48 \mathrm{~km}^{2}(6 \times 8 \mathrm{~km})$ in NPM using aerial photographs. All meadow units within this area were digitized using the ESRI ArcMap ${ }^{\mathrm{TM}} 9.2 \mathrm{SP} 4$ geographical information system software. A total of 192 polygons, each corresponding to a recognizable meadow unit, were identified and mapped (Fig. 2a). From this, we randomly selected 28 polygons (Fig. 1c).

Within each of the sampled meadow polygons, the most spatially representative phytocoenosis (that is, floristically and environmentally homogeneous community, sensu van der Maarel 2005) were visually identified (Fig. 2b). Four circular permanent plots (4 $\mathrm{m}$ diameter) for faecal accumulation rate (FAR) sampling were randomly established in the field within each polygon; however when more than one phytocoenosis was present two permanent plots were randomly positioned in each of the two dominant ones (Fig. 2c). All plots were geo-referenced by GPS and marked with a steel stick. We used circular plots for reducing the bias related to missing faecal pellet group (Neff 1968), and because they are easier to establish in the field as compared, for example, to belt transects (Noor et al. 2010).

\section{Vegetation sampling}

Floristic relevés were conducted in each sampled phytocoenosis following the Zurich-Montpellier school methodology. All present vascular plant species were recorded, together with 




Fig. 1 Study area location: a map of Western Europe highlighting the area of the research; b Montesinho Natural Park boundaries (northeast of Portugal) and study area; $\mathbf{c}$ sampled meadows location within the study area

correspondent abundance-cover values (Braun-Blanquet 1932) relative to the minimal area, which comprised the floristic diversity of the plant community (see MuellerDombois and Ellenberg 1974 for details). Relevés were conducted in June (2008), when most plant species were flowering and easier to identify and because deer are dominantly grazers during this period (Bugalho and Milne 2003). The minimal area (Mueller-Dombois and Ellenberg 1974) of each relevé included at least one of the permanent plots and varied between 10 and $40 \mathrm{~m}^{2}$ (Fig. 2d).

Deer use of meadows

FAR was used as an indicator of spring use of meadow patches. FAR is a method commonly used to estimate deer abundances when data on dung decay is not available (Campbell et al. 2004; Smart et al. 2004) and it can provide reliable information on relative habitat use (Palmer and Truscott 2003). All faecal pellet groups containing at least ten identifiable pellets of similar size, colour and shape
(Palmer and Truscott 2003) were counted in each of the circular permanent plots. Each plot was visited twice, at the beginning and end of spring, and faecal pellets groups counted and removed in each visit.

Patch clustering criteria

The floristic relevés were clustered taking into consideration either floristic composition or gross forage types.

1. Floristic criteria

(a) Phytosociology

For the floristic criteria we used phytosociological classification: phytosociological units were attributed to each floristic relevé following mainly Aguiar (2001) but also the expert knowledge of the authors.

(b) Total cover of plant species

To test the objectivity of the phytosociological approach, we also classified the floristic relevés adopting a common mathematical clustering procedure, considering the total cover of plant species. 
Fig. 2 Schematic

representation of the sampling design steps: a meadow polygons mapping; $\mathbf{b}$ random selection of meadow polygons and visual recognition of plant communities; c random positioning of FAR plots in each recognized vegetation patch; $\mathbf{d}$ vegetation sampling (relevé minimal area schematized by squares and rectangles)
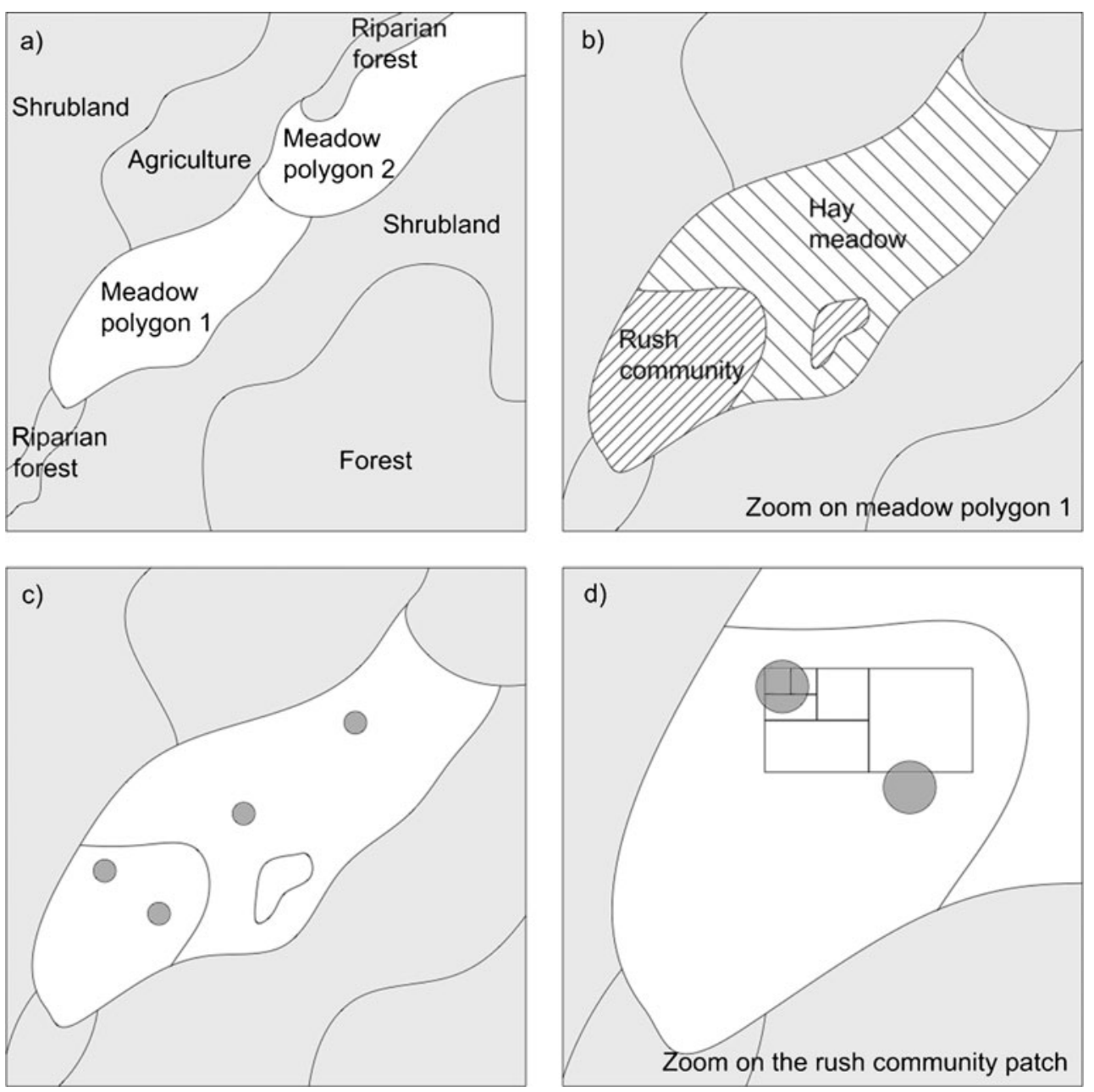

We performed a $k$-means cluster analysis (Hartigan and Wong 1979) on the 50 relevés using the function kmeans (package stats) in R Statistical Software (R Development Core Team 2010) with 10,000 starts using random initial centres and $k$ (number of partitions) from 2 to 25 . To select the optimal number of clusters we used the indicator value index (IndVal), which is a measure of fidelity and relative abundance of a species in a specific cluster (Dufrêne and Legendre 1997). We applied the following cumulative criteria to select the optimal partition, using IndVal and the associated $p$ value obtained by a 10,000 permutation test:

(i) $\max \%$ : select the partition(s) that maximizes the percentage of total clusters with at least one indicator species with $p$ value $<0.05$;

(ii) min IndVal drop: if more than one partition is selected in the previous step, the optimal partition is considered the one which minimizes the drop of IndVal.

IndVal was calculated in $\mathrm{R}$ Statistical Software (R Development Core Team 2010) using the function "indval" of package labdsv (Roberts 2007). IndVal drop for each partition was calculated as follows:

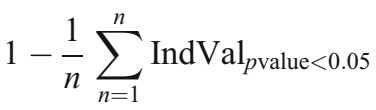

where $n$ is the number of indicator species with $p$ value $<0.05$ in the partition and IndVal the respective indicator value of each species.

(c) Cover of dominant species

In order to test the possibility of discriminating among plant community using less labour-intensive methodology, we clustered meadow patches using the same methodology as in (b) but considering only species with cover equal to or above $25 \%$ - BraunBlanquet's abundance-cover scale was converted into central cover percentage, following MonteiroHenriques (2010). The dominant species criteria relies on the assumption that grazers selectivity depends on the overall nutritive value of that patch, which is associated to the nutritive value of the dominant plant species in that patch (Dumont et al. 
2002). Records of dominant plant species are also less time consuming which could optimize field sampling.

2. Gross forage types

(a) Graminoids/forbs ratio

Recorded species were divided into graminoids (including grasses, sedges and rushes) and forbs. These two gross categories tend to differ in palatability and nutritive value (Clauss et al. 2007; Shipley 1999). Forbs usually have higher digestibility value throughout the year, as compared to graminoids and heaths (Gordon 1989a).

The total cover of graminoids and forbs was estimated within each plant community and samples clustered according to the following range of graminoids/forbs ratios: group 1, less than 1; group 2, 1 to 2 ; group 3, 2 to 4 ; group 4, 4 to 10 ; group 5, more than 10 .

(b) Cover of legumes

According to other researches, ruminants have usually higher voluntary intake rates for legumes as compared, for example, with grasses of similar digestibility (Fales and Fritz 2007; van Soest 1994). Therefore, the percentage cover of this forage class might affect deer use of meadow patches. Clusters were obtained by estimating total percentage cover of legumes within the sampled plant community and by applying the following threshold values for cover of legumes: group 1, $0 \%$; group 2, less than $2.5 \%$; group 3, $2.5 \%$ to $10 \%$; group $4,10 \%$ to $25 \%$, group 5 , more than $25 \%$.

\section{Statistical analyses}

We used Fisher exact tests (Fisher 1990, 1935) to assess if there were significant differences in FAR among patches defined by different criteria. We applied the fisher.test function (package stats) in R Statistical Software version 2.13.0 (R Development Core Team 2010). FAR mean values of within relevé plots were used. Because there was a high number of zero counts, as it frequently occurs when collecting such type of data (Gu and Swihart 2004), we firstly used presence-absence data and subsequently grouped the faecal data into three classes of abundance: $0 ; 0$ to 1 ; and more than 1 faecal group, in order to assess whether information relative to abundance was valuable.

Within each clustering criteria, patch type preference was evaluated using Jacobs modification of Ivlev's electivity index (Jacobs 1974).

For Jacobs index, $D_{i}=\left(r_{i}-p_{i}\right) /\left(r_{i}+p_{i}-2 r_{i} p_{i}\right), r_{i}$ is the proportion of faecal pellets groups in patch type $i$ within the total sum of occurrences, and $p_{i}$ the proportion of patch type $i$ within the existing meadows sample, which is assumed as representative of the study area. $D_{i}$ varies from -1 (never used) to +1 (exclusively used) with values equal to or around zero meaning that patch type use can be considered random.

\section{Results}

Patch clustering criteria

A total of 50 relevés (available in the Electronic Supplementary Material 1-floristic relevés and information on the clusters according to the used criteria) were realized within the sampled meadows of the 28 meadows, 22 comprised two different phytocoenosis, whereas the remaining six were considered floristically homogeneous, and therefore were characterized by only one relevé.

Six different phytosociological units were ascribed to the floristic relevés while three of them had no clear phytosociological classification (Table 1) and were excluded from the statistical analyses.

The groups generated using total cover of plant species and cover of dominant species ( $k$-means clusters) were consistent with the phytosociological units; the three unclassified relevés were clustered in a single group (Table 1). Five patch clusters were obtained when considering the graminoids/forbs ratio and cover of legumes (Table 2).

Red deer use of meadow patches, clustered according to the five criteria analysed is resumed in Table 3 .

There were significant differences among FAR considering patch clustered according to phytosociology $\left(P_{\text {phyto }}=0.04\right.$, presence/absence data; $P_{\text {phyto }}=0.05$, with $0,0-1$ and $>1$ classes).

When considering phytosociological units, the patches belonging to the Community of Agrostis $\times$ fouilladei and Arrhenatherum elatius subsp. bulbosum (ARRH) were selected more than randomly expected $\left(D_{\mathrm{ARRH}}=0.64\right)$. Communities of Hyperico undulati-Juncetum acutiflori (JUNC) and Avenula sulcata (AVESU) were used randomly $\left(D_{\mathrm{JUNC}}=0.08 ; D_{\mathrm{AVESUL}}=-0.02\right)$, whilst those of Agrostio castellanae-Cynosuretum cristati (CYN), and of Festuca rothmaleri and Nardus stricta (NARD) were selected less than randomly expected $\left(D_{\mathrm{CYN}}=-0.2 ; D_{\mathrm{NARD}}=-0.23\right)$ and those of Brachypodium rupestre (BRACHY) were avoided $\left(D_{\mathrm{BRACHY}}=-1\right.$; Table 4$)$.

Similar results were obtained when considering clustering criteria based on both total and dominant plant species: the marginal differences were only due to the unclassified plots excluded from the phytosociological clusters $\left(P_{k-\mathrm{m}}=\right.$ 0.05 , presence/absence data; $P_{k-\mathrm{m}}=0.06$, with 0,1 and $>1$ classes). Both clusters based on cover of legumes and ratio of graminoids/forbs did not explain red deer selection of 
Table 1 Phytosociological units (associations and communities) attributed to the floristic relevés, relative abbreviations, number of relevés in each cluster and corresponding groups according to the total cover of plant species and cover of dominant species criteria $(k$-m tot/dom)

\begin{tabular}{|c|c|c|c|c|}
\hline Phytosociological unit & Abbreviation & $\begin{array}{l}\text { Number of } \\
\text { relevés }\end{array}$ & $\begin{array}{l}\text { Number of } \\
\text { plots }\end{array}$ & $\begin{array}{l}k \text {-m tot/ } \\
\text { dom }\end{array}$ \\
\hline Community of Avenula sulcata & AVESU & 16 & 36 & Group1 \\
\hline Community of Agrostis $\times$ fouilladei and Arrhenatherum elatius subsp. bulbosum & ARRH & 5 & 12 & Group2 \\
\hline Community of Brachypodium rupestre & BRACHY & 7 & 16 & Group3 \\
\hline Agrostio castellanae-Cynosuretum cristati & CYN & 12 & 28 & Group4 \\
\hline Hyperico undulati-Juncetum acutiflori & JUNC & 3 & 6 & Group5 \\
\hline Community of Festuca rothmaleri and Nardus stricta & NARD & 4 & 8 & Group6 \\
\hline Unclassified & & 3 & 6 & Group7 \\
\hline
\end{tabular}

feeding patches $\left(P_{\text {leg } \%}=0.18\right.$, presence/absence data; $P_{\text {leg } \%}=$ 0.34 , with 0,1 and $>1$ classes; $P_{\text {gram } / \text { forb }}=0.68$, presence/ absence data; $P_{\text {gram/forb }}=0.82$, with 0,1 and $>1$ classes ).

\section{Discussion}

Phytosociology has been commonly used to describe plant communities as, for example, the classified 'natural habitats' of the Natura 2000 network, a pan-European network of protected habitats (European Commission 2007), but less utilized in wildlife research (Putfarken et al. 2008). Most of the meadow patches (94\%) analysed in this study could be ascribed to phytosociological units and there were significant differences in deer FAR among such units. Because sampling was random, floristic records were not expected to necessarily fall into "typical stands" (Roleček et al. 2007), hence including some marginal/recently disturbed communities for which the identification of phytosociological units at the lower hierarchical level (i.e. association or "Community of") was not possible. The high classification power of phytosociology may have resulted from the physical characteristics of the analysed meadows, which are mostly "discrete" units, separated by traditional irrigation channels and natural waterlines, but also by stone walls or fences, and are characterized by a peculiar pattern of vegetation disturbance related to traditional management, which is distributed uniformly in space and regularly in time, namely: continuous irrigation (throughout the year), extensive livestock grazing from the end of summer to the beginning of spring, and hay harvesting in summer.

Patches defined by total cover of plant species or cover of the dominant ones were consistent with those based on phytosociology and produced similar results. Such findings showed the importance of dominant species in characterizing meadow plant communities particularly when the geographic domain is restricted, like in our survey. Results also suggested that less labour-intensive criteria, such as dominant species cover, might be used as proxies of phytosociological units. This is particularly useful in Mediterranean meadows, which usually have a high diversity of plant species (Puerto et al. 1990).

Red deer avoided B. rupestre-dominated communities (BRACHY) while selecting those dominated by Agrostis $\times$ fouilladei and A. elatius subsp. bulbosum (ARRH). B. rupestre is a grass species with a very low nutritive value (García 1992), which tends to form tall and thick tufts that are deterrent to grazing. ARRH communities are rich in species of medium to high nutritive value such as $A$. bulbosum, Agrostis $\times$ fouilladei, A. capillaris, and in our study area they were also rich in high-quality legumes (e.g. Vicia spp.). Additionally, patches of legumes shrubs, such as Cytisus spp. and Adenocarpus spp., heavily browsed by deer (Bellu, personal observation), occurred in the area surrounding ARRH patches. These factors may have also contributed to explain deer preference for these communities. Rush communities (H. undulati-J. acutiflori patches-JUNC) were
Table 2 Number of relevés in each cluster of the graminoids/ forbs ratio and cover of legumes criteria

\begin{tabular}{lccccc}
\hline & \multicolumn{3}{l}{ Gram/forb } & & \multicolumn{2}{l}{$\%$ legumes } \\
\cline { 2 - 3 } \cline { 5 - 6 } \cline { 5 - 6 } & Number of relevés & Number of plots & & Number of relevés & Number of plots \\
\hline Group 1 & 8 & 18 & & 9 & 18 \\
Group 2 & 12 & 32 & & 18 & 44 \\
Group 3 & 14 & 30 & & 5 & 24 \\
Group 4 & 6 & 12 & & 7 & 12 \\
Group 5 & 10 & 20 & & 11 & 24 \\
\hline
\end{tabular}


Table 3 Red deer use of meadow patches clustered according to the five criteria (FPG: number of faecal pellet groups counted for each patch type)

\begin{tabular}{|c|c|c|c|c|c|}
\hline & Presence & Absence & Tot FPG & Mean FPG/relevé & Mean FPG/plot \\
\hline \multicolumn{6}{|c|}{ Phytosociology/ Total cover of plant species and cover of dominant species } \\
\hline AVESU/Group1 & 14 & 22 & 18 & 1.1 & 0.5 \\
\hline ARRH/Group2 & 8 & 4 & 19 & 3.8 & 1.6 \\
\hline BRACHY/Group3 & 0 & 16 & 0 & 0 & 0 \\
\hline CYN/Group4 & 6 & 22 & 10 & 0.8 & 0.4 \\
\hline JUNC/Group5 & 3 & 3 & 4 & 1.3 & 0.7 \\
\hline NARD/Group6 & 3 & 5 & 3 & 0.8 & 0.4 \\
\hline -/Group7 & 2 & 4 & 5 & 1.7 & 0.8 \\
\hline \multicolumn{6}{|c|}{ Graminoids/forbs ratio } \\
\hline Group1 & 9 & 9 & 17 & 2.1 & 0.9 \\
\hline Group2 & 12 & 20 & 20 & 1.7 & 0.6 \\
\hline Group3 & 7 & 23 & 11 & 0.8 & 0.4 \\
\hline Group4 & 3 & 9 & 4 & 0.7 & 0.3 \\
\hline Group5 & 5 & 15 & 7 & 0.7 & 0.4 \\
\hline \multicolumn{6}{|l|}{ Cover of legumes } \\
\hline Group1 & 5 & 13 & 10 & 1.1 & 0.6 \\
\hline Group2 & 14 & 30 & 19 & 1.1 & 0.4 \\
\hline Group3 & 3 & 21 & 3 & 0.3 & 0.1 \\
\hline Group4 & 6 & 6 & 10 & 2 & 0.8 \\
\hline Group5 & 8 & 6 & 17 & 2.4 & 1.2 \\
\hline
\end{tabular}

used in proportion to availability (Table 4): red deer use of marshes, although random in our case, was shown to occur in temperate climate in the isle of Rhum, Scotland (CluttonBrock et al. 1982). A. sulcata-dominated communities (AVESU) were used also randomly. AVESU communities, although being the most frequent type in our sample, can be considered as marginal within the meadows system, meaning that they are usually confined farther from the water courses or irrigation ditches, frequently on the steeper sides of a meadow, i.e. on drier areas. These communities also tend to spread out when meadows located farther from the watercourses are abandoned, i.e. when management and above all irrigation ceases. A. castellanae-C. cristati patches (CYN) shown moderate avoidance. Most of the sampled CYN patches were within currently managed meadows, which, due to irrigation, have relatively constant soil moisture and consequently an extended vegetative season, both during summer and winter. Additionally, these communities are periodically grazed and manured by domestic cattle, generating high nutritive grazing lawns (Mládek et al. 2011): floristic composition comprises species such as the high-quality grasses Cynosurus cristatus, Holcus lanatus or Anthoxanthum odoratum, forbs like Plantago lanceolata, Sanguisorba minor, and legumes such Trifolium spp. that are very palatable for deer (Arsenault and Owen-Smith 2002; Gordon 1988; Vavra 2005), and thus would be expected to be preferred by deer. A possible
Table 4 Jacobs's selectivity indexes $\left(D_{i}\right)$ for the clusters based on floristic criteria (total cover of plant species and cover of dominant species are consistent with phytosociological units, and the seventh group corresponds to the three relevés not classified by phytosociology, as shown in Table 1), on graminoids/forbs ratio and on legumes cover

\begin{tabular}{llllllr}
\hline Phytosociology & $D_{i}$ & $k$-m tot/dom & $D_{i}$ & Gram/forbs & $D_{i}$ & \% legumes \\
\hline AVESU & -0.02 & Group1 & -0.03 & Group1 & 0.36 & Group1 \\
ARRH & 0.64 & Group2 & 0.62 & Group2 & 0.24 & Group2 \\
BRACHY & -1 & Group3 & -1 & Group3 & -0.26 & Group3 \\
CYN & -0.2 & Group4 & -0.21 & Group4 & -0.3 & Group4 \\
JUNC & 0.08 & Group5 & 0.07 & Group5 & -0.3 & Group5 \\
NARD & -0.23 & Group6 & -0.24 & & & 0.08 \\
& & Group7 & 0.18 & & & \\
\hline
\end{tabular}


explanation for this moderate avoidance could be the fact that the majority of CYN meadows are set aside during spring, i.e. they are not grazed, as part of the traditional grazing rotation. As a consequence, the herb layer, rich in grass species, rapidly grows to maturity, and overall digestibility and palatability declines towards the end of the season (Kilcher 1981). However, further experiments will be needed to test this hypothesis. In addition, the CYN type meadows which are not set aside are grazed by communitarian sheep flocks, which may act as a deterrent for deer grazing (Osborne 1984). Patches belonging to the community of $F$. rothmaleri and N. stricta (NARD) were also used less than random expectation: NARD communities are characterized by dominance, or at least very abundant presence, of low palatable $N$. stricta.

There were no significant differences in FAR when using clusters based on graminoids/forbs ratio. The graminoids and forbs classes comprised a highly heterogeneous mixture of plant species, with different physical properties, chemical composition, and nutritional values (Hanley 1997). Oversimplification of the plant species diversity into broad categories such as graminoids/forbs may have prevented the evidence of patterns of selectivity, although patches with a higher proportion of forbs had higher selectivity indexes (groups 1 and 2, Table 4), as established by other authors (Dumont et al. 2005).

Similarly, no differences in deer FAR were found when using patches clustered according to cover of legumes, although those patches richer in legumes (group 4 and 5, Table 4) were selected more than the others. Preference for patches with an increasing availability of nutritive species such as legumes has been recorded in different studies of ruminant nutritional ecology (Dumont et al. 2002; Semiadil et al. 1995).

Patch definition criteria affected results of deer meadow use pattern. Specifically, clusters based on floristic classification explained red deer use of meadow patches better than gross forage classes. Our results relate to a specific phenological season when meadow forage is growing and thus availability and nutritive quality of the herbaceous layer are higher. The richer and more abundant forage may have resulted in a higher selective ability at the patch level in our study. Possibly, deer perception of vegetation patches and thus their selective ability decrease with the declining of forage nutritional quality (Owen-Smith and Novellie 1982). Beyond plant species composition and abundances, patch selection by deer is affected by other factors, which were out of the scope of present study. For example, topography and associated elements as slope and aspect may affect plant phenological stages and forage nutritional value (Sharif and West 1968; Smallidge et al. 2010). Our results indicate that phytosociological classifications or proxy methodologies such as criteria based on cover of dominant plant species may prove useful in wildlife research, particularly at finer scales of analysis. However, given the hierarchical structure of foraging behaviour (Bailey et al. 1996; Senft et al. 1987), other factors operating at broader scales must be integrated when explaining the foraging behaviour of large mammalian herbivores.

Acknowledgements Annalisa Bellu was financed by a $\mathrm{PhD}$ grant from Fundação para a Ciência e a Tecnologia (SRFH/BD/24134/2005), within the programme of National funds of the Ministério da Ciência, Tecnologia e Ensino Superior (MCTES). The authors would like to thank two anonymous reviewers for their valuable comments on a previous draft of the manuscript.

\section{References}

Aguiar CFG (2001) Flora e vegetação da Serra de Nogueira e do Parque Natural de Montesinho. PhD Thesis, Technical University of Lisbon

Arsenault V, Owen-Smith N (2002) Facilitation versus competition in grazing herbivore assemblages. Oikos 97:313-318

Bailey DW, Gross J, Laca E, Rittenhouse L, Coughenour M, Swift D, Sims P (1996) Mechanisms that result in large herbivore grazing distribution patterns. J Range Manag 49:386-400

Bowyer RT, Kie JG (2006) Effects of scale on interpreting life-history characteristics of ungulates and carnivores. Divers Distrib 12 (3):244-257

Braun-Blanquet J (1932) Plant sociology — the study of plant communities. McGraw-Hill, New York

Bugalho MN, Milne JA (2003) The composition of the diet of red deer (Cervus elaphus) in a Mediterranean environment: a case of summer nutritional constraint? For Ecol Manag 181(1-2):23-29

Bugalho MN, Lecomte X, Gonçalves M, Caldeira MC, Branco M (2011) Establishing grazing and grazing-excluded patches increases plant and invertebrate diversity in a Mediterranean oak woodland. For Ecol Manag 261(11):2133-2139

Campbell D, Swanson GM, Sales J (2004) Comparing the precision and cost-effectiveness of faecal pellet group count methods. J Appl Ecol 41(6):1185-1196

Chapman DF, Parsons AJ, Cosgrove GP, Barker DJ, Marotti DM, Venning KJ, Rutter SM, Hill J, Thompson AN (2007) Impacts of spatial patterns in pasture on animal grazing behavior, intake, and performance. Crop Sci 47(1):399-415

Clauss M, Kaiser T, Hummel J (2007) The morphophysiological adaptations of browsing and grazing mammals. In: Gordon P (ed) The ecology of browsing and grazing. Springer, Berlin, pp 47-88

Clutton-Brock TH, Guinness FE, Albon SD (1982) Red deer behavior and ecology of two sexes. The University of Chicago Press, Chicago

Cote SD, Rooney TP, Tremblay J-P, Dussault C, Waller DM (2004) Ecological impacts of deer overabundance. Annu Rev Ecol Evol Syst 35(1):113-147

Coulon A, Morellet N, Goulard M, Cargnelutti B, Angibault J-M, Hewison A (2008) Inferring the effects of landscape structure on roe deer (Capreolus capreolus) movements using a step selection function. Landsc Ecol 23(5):603-614

Dufrêne M, Legendre P (1997) Species assemblages and indicator species: the need for a flexible asymmetrical approach. Ecol Monogr 67(3):345-366

Dumont B, Carrère P, D'Hour P (2002) Foraging in patchy grasslands: diet selection by sheep and cattle is affected by the 
abundance and spatial distribution of preferred species. Anim Res 51(5):367-381

Dumont B, Renaud PC, Morellet N, Mallet C, Anglard F, VerheydenTixier H (2005) Seasonal variations of red deer selectivity on a mixed forest edge. Anim Res 54(5):369-381

European Commission (2007) Interpretation manual of European Union Habitats-EUR 27. European Commission DG Environment

Fales SL, Fritz JO (2007) Factors affecting forage quality. In: Barnes RF, Miller DA, Nelson CJ (eds) Forages: the Science of Grassland Agriculture. Blackwell Publishing, pp 569-580

Fisher RA (1935) The logic of inductive inference. J R Stat Soc 98:3982

Fisher RA (1990) Statistical methods, experimental design, and scientific inference: a re-issue of statistical methods for research workers, the design of experiments, and statistical methods and scientific inference. Oxford University Press, USA

Fortin D, Beyer HL, Boyce MS, Smith DW, Duchesne T, Mao JS (2005) Wolves influence elk movements: behavior shapes a trophic cascade in Yellowstone National Park. Ecol 86(5):1320-1330

García A (1992) Conserving the species-rich meadows of Europe. Agric Ecosyst Environ 40:219-232

Gordon IJ (1988) Facilitation of red deer grazing by cattle and its impact on red deer performance. J Appl Ecol 25(1):1-9

Gordon IJ (1989a) Vegetation community selection by ungulates on the Isle of Rhum. I. Food supply. J Appl Ecol 26(1):35-51

Gordon IJ (1989b) Vegetation community selection by ungulates on the Isle of Rhum. II. Vegetation community selection. J Appl Ecol 26(1):53-64

Griffiths WM, Hodgson J, Arnold GC (2003) The influence of sward canopy structure on foraging decisions by grazing cattle. I. patch selection. Grass Forage Sci 58:112-124

Gu W, Swihart RK (2004) Absent or undetected? Effects of nondetection of species occurrence on wildlife-habitat models. Biol Conserv 116(2):195-203

Hanley TA (1997) A nutritional view of understanding and complexity in the problem of diet selection by deer (cervidae). Oikos 79 (2):209-218

Hartigan JA, Wong MA (1979) Algorithm AS 136: a k-means clustering algorithm. J R Stat Soc Ser C Appl Stat 28(1):100-108

Hebblewhite M, Merrill EH, McDonald TL (2005) Spatial decomposition of predation risk using resource selection functions: an example in a wolf-elk predator-prey system. Oikos 111(1):101-111

Huntly N (1991) Herbivores and the dynamics of communities and ecosystems. Annu Rev Ecol Syst 22:477-503

Jacobs J (1974) Quantitative measurement of food selection: a modification of the forage ratio and Ivlev's electivity index. Oecologia 14(4):413-417

Johnson C, Parker K, Heard D (2001) Foraging across a variable landscape: behavioral decisions made by woodland caribou at multiple spatial scales. Oecologia 127(4):590-602

Kie JG, Bowyer RT, Nicholson MC, Boroski BB, Loft ER (2002) Landscape heterogeneity at differing scales: effects on spatial distribution of mule deer. Ecol 83(2):530-544

Kie JG, Ager AA, Bowyer RT (2005) Landscape-level movements of North American elk (Cervus elaphus): effects of habitat patch structure and topography. Landsc Ecol 20(3):289-300

Kilcher MR (1981) Plant development, stage of maturity and nutrient composition. J Range Manag 34(5):363-364

Langvatn R, Hanley TA (1993) Feeding-patch choice by red deer in relation to foraging efficiency. Oecologia 95(2):164-170

Loehle C (2011) Complexity and the problem of ill-posed questions in ecology. Ecol Complex 8:60-67

Mládek J, Hejcman M, Hejduk S, Duchoslav M, Pavlů V (2011) Community seasonal development enables late defoliation without loss of forage quality in semi-natural grasslands. Folia Geobot 46(1):17-34
Monteiro-Henriques T (2010) Landscape and phytosociology of the Paiva River's hydrographical basin. PhD Thesis, Technical University of Lisbon

Mueller-Dombois D, Ellenberg H (1974) Aims and methods of vegetation ecology. Wiley, New York

Mysterud A, Larsen PK, Ims RA, Østbye E (1999) Habitat selection by roe deer and sheep: does habitat ranking reflect resource availability? Can J Zool 77(5):776-783

Neff DJ (1968) The pellet-group count technique for big game trend, census, and distribution: a review. J Wildl Manag 32 (3):597-614

Noor A, Habib B, Kumar S (2010) Effects of plot size and shape on the encounter rate of ungulate faecal pellet groups and abundance estimate precision. Curr Sci 99(6):800-804

Osborne BC (1984) Habitat use by red deer (Cervus elaphus) and hill sheep in the west Highlands. J Appl Ecol 21:497506

Owen-Smith N, Novellie P (1982) What should a clever ungulate eat? Am Nat 19:151-178

Paiva J (2004). Estimating red and roe deer population densities in Parque Natural de Montesinho. First degree thesis, University of Coimbra

Palmer SCF, Truscott AM (2003) Seasonal habitat use and browsing by deer in Caledonian pinewoods. For Ecol Manag 174(13):149-166

Partl E, Szinovatz V, Reimoser F, Schweiger-Adler J (2002) Forest restoration and browsing impact by roe deer. For Ecol Manag 159 (1-2):87-100

Puerto A, Rico M, Matías MD, García JA (1990) Variation in structure and diversity in Mediterranean grasslands related to trophic status and grazing intensity. J Veg Sci 1(4):445-452

Putfarken D, Dengler J, Lehmann S, Härdtle W (2008) Site use of grazing cattle and sheep in a large-scale pasture landscape: a GPS/ GIS assessment. Appl Anim Behav Sci 111:54-67

R Development Core Team (2010) R: a language and environment for statistical computing. R Foundation for Statistical Computing, Vienna

Rivas-Martínez S (2007) Mapa de series, geoseries y geopermaseries de vegetación de España. Itinera Geobot 17:5-436

Roberts DW (2007) labdsv: ordination and multivariate analysis for ecology. R package version 1.3-1. http://ecology.msu.montana. edu/labdsv/R

Roleček J, Chytrý M, Hájek M, Lvončík S, Tichý L (2007) Sampling design in large-scale vegetation studies: do not sacrifice ecological thinking to statistical purism! Folia Geobot 42(2): 199-208

Rooney TP, Waller DM (2003) Direct and indirect effects of whitetailed deer in forest ecosystems. For Ecol Manag 181(1-2):165176

Semiadil G, Barry TN, Muir PD, Hodgson J (1995) Dietary preferences of sambar (Cervus unicolor) and red deer (Cervus elaphus) offered browse, forage legume and grass species. J Agric Sci 125(1):99-107

Senft RL, Coughenour MB, Bailey DW, Rittenhouse LR, Sala OE, Swift DM (1987) Large herbivore foraging and ecological hierarchies. BioSci 37(11):789-799

Sharif CM, West NE (1968) Forage moisture variations on mountain summer range. J Range Manag 21:228-235

Shipley LA (1999) Grazers and browsers: how digestive morphology affects diet selection. In: Launchbaugh KL, Sanders KD, Mosley JC (eds) Grazing behaviour of livestock and wildlife. Univ. of Idaho, Moscow, pp 20-27

Smallidge ST, Baker TT, VanLeeuwen D, Gould WR, Thompson BC (2010) Elk distributions relative to spring normalized difference vegetation index values. Int J Ecol 2010:110 
Smart JCR, Ward AI, Whitehead PCL (2004) Monitoring woodland deer populations in the UK: an imprecise science. Mamm Rev 34 (1-2):99-114

van der Maarel E (2005) Vegetation ecology — an overview. In: van der Maarel E (ed) Vegetation ecology. Blackwell, Oxford, pp 1-51

van Soest PJ (ed) (1994) Nutritional ecology of the ruminant. Cornell University Press, Ithaca
Vavra M (2005) Livestock grazing and wildlife: developing compatibilities. Rangel Ecol Manag 58:128-134

WallisDeVries MF, Laca EA, Demment MW (1999) The importance of scale of patchiness for selectivity in grazing herbivores. Oecologia 121(3):355-363

Wiens JA (1976) Population responses to patchy environments. Annu Rev Ecol Syst 7:81-120 